\title{
Household Chaos and Child Behavior Problems Predict Maternal Well-being
}

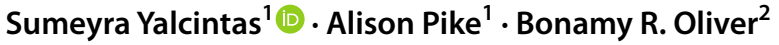

Accepted: 22 August 2021 / Published online: 1 September 2021

(c) The Author(s) 2021

\begin{abstract}
The aim of the study was to investigate predictors of maternal well-being in mothers of twins. As well as being important in its own right, maternal well-being is a crucial predictor of parenting (Belsky in Child Dev. 55(1):83, 1984). Based on previous research (Pike et al. in Int J Beh Dev. 30(1):55-66, 2006) we expected that household chaos (Confusion, Hubbub, and Order) and child behavior problems would predict maternal depression, stress and anxiety. The data for the study was taken from the Twins, Family and Behavior Study (TFaB) -- a longitudinal UK study of twins born in 2009 and 2010. One hundred and fiftyeight mothers of twins $\left(M_{\text {child age }}=6.01\right.$ years, $\left.S D_{\text {age }}=0.50\right)$ reported on household chaos, child disruptive behaviors and their own well-being. Higher levels of household chaos were linked to maternal depressive, anxiety and stress related symptoms. More child behavior problems were related to more depressive and stress symptoms but not anxiety. The findings show promise for future research investigating different types of maternal well-being and suggested practical implications, such as intervening on concrete aspects of household chaos to improve maternal well-being.
\end{abstract}

Keywords Maternal well-being $\cdot$ Household organization $\cdot$ Household chaos $\cdot$ Child behavior problems

Maternal well-being (e.g., depression, stress and anxiety) is critical both for mother and child. The present study hypothesized that household disorganization would predict maternal well-being based on previous research [2] and further tested child behavior problems as another predictor. The aim of the study was to examine relationships between household chaos, child behavior problems and maternal well-being, and to uncover patterns of

Sumeyra Yalcintas

S.Yalcintas@sussex.ac.uk

Alison Pike

alisonp@sussex.ac.uk

Bonamy R. Oliver

b.oliver@ucl.ac.uk

1 School of Psychology, University of Sussex, Brighton BN1 9RH, UK

2 Dept Psychology and Human Development, UCL Institute of Education, University College London, London, UK 
differentiation for well-being. The sample consisted of families with twins, such families require more organization and effort in parenting. Specifically, we investigated whether household chaos and child behavior problems predicted maternal depression, stress and anxiety in similar or distinctive ways.

\section{Maternal Well-being}

Studying maternal well-being is important, not only for mothers, but also because it is predictive of better parenting. For example, better maternal mental health predicts better quality parenting [1] and secure child attachments [3]. Conversely, depressed mothers are more hostile [4], demonstrate fewer sensitive behaviors [5] toward their children, and have more negative interactions with their infants [6]. Therefore, studying predictors of maternal wellbeing is important for understanding the mother-child relationship. Importantly, existing studies largely investigate one aspect of maternal well-being (e.g., depression) or several aspects as a composite (e.g., depression, stress and anxiety in combination). However, there are theoretical reasons to consider differentiating well-being (studying depression, anxiety and stress individually). The Tripartite Model of Anxiety and Depression [7] has been used to explain comorbidity of depression and anxiety, dividing them into physiological arousal and positive and negative affect. Studies investigating mothers during the prenatal and postnatal periods have demonstrated distinct findings for maternal anxiety and depression. For example, children's internalizing problems are influenced by maternal depression but not by anxiety [7]. Yet the research on differentiation of maternal well-being is limited. To address this gap, we defined maternal well-being as the level of depression, stress and anxiety symptoms reported by mothers, aiming to uncover patterns of differentiation for well-being.

\section{Chaos, Child Behavior Problems, and Maternal Well-Being}

Homes low in regularity, and high in noise and crowding, have been defined as high in household chaos [8]. Higher levels of household chaos have been related to maternal depression and stress [2], as well as with unsupportive behaviors of mothers toward their children [9]. The role of child behavior problems has also been studied in relation to maternal well-being. For example, children of depressed mothers have more behavior problems than children with non-depressed mothers [10]. Although such associations are commonly conceptualized as parent to child effects, there is also evidence of bidirectional effects,child characteristics can also influence parents. Research on children's temperament, for example, demonstrates that mothers of children with difficult temperaments are at risk of depression and stress [11-13].

\section{The Present Study}

The sample for the current study was families with twins, families that typically experience additional stress. Given the links between household chaos, maternal well-being, parenting and child behavior problems, we hypothesized a model whereby household chaos and child behavior problems predicted maternal well-being. Previous research indicates that 
household chaos is associated with conduct problems, impulsivity and delinquency [14, 15], externalizing behaviors and aggression, [16] and diverse child adjustment problems $[17,18]$. Due to the probable correlation among our predictors, we investigated independent predictions from household chaos and child behavior problems to maternal well-being, as well as examining their prediction as a whole. Specifically, higher levels of household chaos and child behavior problems were hypothesized to predict higher levels of depression, anxiety and stress. Additionally, we aimed to uncover possible differentiation of these aspects of maternal well-being.

\section{Method}

\section{Participants and Procedure}

Data was drawn from the Twins, Family and Behavior Study (TFaB) -- a longitudinal UK study of twins born in 2009 and 2010, that investigates family relationships and children's behaviors. The data for this study was cross-sectional. In total, 158 mothers $\left(M_{\text {age }}=38.14\right.$ years; SDage $=4.32$ years) of twins reported on levels of household chaos, child behavior problems and their own symptoms of depression, anxiety and stress, $\left(M_{\text {child age }}=6.01\right.$ years, SDage $=0.50$ years). Fifty-four of the twins were monozygotic and 101 were dizygotic, with 3 pairs of unclassified zygosity. One-hundred-and-forty-three $(91 \%)$ mothers were married or cohabiting with a partner. Mothers were highly educated, $71.3 \%$ of the sample reported having an undergraduate or higher degree, and only $0.6 \%$ of mothers reported having no qualification. Ethnicity information was not collected in this sample. Household income ranged between less than $£ 5,000$ and more than $£ 100,000$, with a median response of $£ 40,000$ - $£ 49,000$. Mothers completed postal questionnaires for all study variables.

\section{Measures}

Household Chaos The short version of the Confusion, Hubbub, and Order Scale (CHAOS; [10]) was used to assess household chaos, and consisted of 6 items. Mothers rated the items on a 5-point scale $(1=$ definitely untrue, $5=$ definitely true $)$. Example items are "The children have a regular bedtime routine (e.g., same bed each night, a bath before bed, reading a story)" (reverse-scored) and "It is a real zoo in our home". The Cronbach's $\alpha$ was .67.

Child Behavior Problems The Eyberg Child Behavior Inventory (ECBI; [19]) was given to mothers to assess child behavior problems. The response format was a 7-point Likert type scale $(1=$ never, $7=$ always $)$ and the questionnaire has 36 items. Example items are "Destroys toys and other objects" and "Acts defiant when told to do something". Items were summed, with higher scores indicating more disruptive behaviors. The correlation between maternal reports of their twins' behavior problems was $r=.81$. Due to this substantial twin similarity, we created a single variable for each family. The Cronbach $\alpha$ for this measure was .93 .

Maternal Well-Being The Depression Anxiety Stress Scales (DASS-21; [20]) was used to measure maternal well-being. The questionnaire has 3 sub-scales, each of seven items (note that in the current study one item measuring depression was inadvertently missing). 
Mothers were asked to rate how much each statement applied to them over the past week on a 4-point scale $(0=$ did not apply to me at all, $3=$ applied to me very much or most of the time). A sample item for depression is "I felt that I had nothing to look forward to," for anxiety "I felt I was close to panic," and for stress "I found it difficult to relax." Scores for each subscale were summed and multiplied by 2. Cronbach's $\alpha$ values were good for depression $(\alpha=.82)$ and stress $(\alpha=.77)$ subscales, and reasonable for anxiety $(\alpha=.62)$.

\section{Results}

\section{Preliminary Analysis}

Table 1 contains correlations and descriptive statistics among all study variables. As expected, higher levels of chaos were related to more depression, stress and anxiety symptoms, and also to more child behavior problems $(r=.39, p<.001)$. More child behavior problems were related to more maternal depression $(r=.31, p<.001)$, and stress $(r=.31$, $p<.001)$ but not more anxiety. Socioeconomic status, maternal age, educational level and zygosity of twins were not related with maternal well-being, so we did not control for these variables in the main analysis.

\section{Multiple Regression Analysis}

To understand independent contributions of household chaos and child behavior problems to maternal well-being, three multiple regression analyses were conducted (see Table 2). For depression, the entire model was significant $F(2,154)=12.41, p<.001$, explaining $13 \%$ of the variation. Both chaos $(B=.23, t=2.86, p<.05)$ and child behavior problems $(B=.21, t=2.62, p<.05)$ significantly predicted depression. However, for anxiety, the results were slightly different. The overall model was significant $F(2,154)=4.49, p<.05$, explaining $5 \%$ of the variation. The only significant predictor was chaos $(B=19, t=2.32$, $p<.05)$. Finally, for stress the model was very similar to depression, $F(2,154)=11.33, p$ $<.001$, explaining $12 \%$ of the variation, with both the predictors chaos $(B=.19, t=2.35$, $p<.05)$ and child behavior problems $(B=.23, t=2.88, p<.05)$ providing significant prediction.

Table 1 Descriptive Statistics \& Bivariate Relations

\begin{tabular}{|c|c|c|c|c|c|}
\hline Variable & 1 & 2 & 3 & 4 & 5 \\
\hline 1. CHAOS & & $.32 * *$ & $.23 *$ & $.29 * *$ & $.39 * *$ \\
\hline 2. Depression & & & $.61 * *$ & $.54 * *$ & $.31 * *$ \\
\hline 3. Anxiety & & & & $.44 * *$ & .15 \\
\hline 4. Stress & & & & & $.31 * *$ \\
\hline \multicolumn{6}{|c|}{$\begin{array}{l}\text { 5.Child Behavior } \\
\text { Problems }\end{array}$} \\
\hline Mean (SD) & $2.39(.63)$ & $3.52(4.39)$ & $2.82(3.61)$ & $9.92(5.63)$ & $3.10(.62)$ \\
\hline Range & $1.17-4.00$ & $0-30$ & $0-20$ & $0-32$ & $1.66-5.14$ \\
\hline
\end{tabular}

$* p<.05 ; * * p<.001$ 
Table 2 Multiple Regression Models for 3 Well-being Variables

\begin{tabular}{llllllll}
\hline & $t$ & $p$ & $B$ & $F$ & $d f$ & $p$ & Adj $R^{2}$ \\
\hline $\begin{array}{l}\text { Depression } \\
\text { Overall Model }\end{array}$ & & & & & & & \\
Chaos & 2.86 & .005 & .23 & & & & \\
CBP & 2.62 & .010 & .21 & & & & \\
Anxiety & & & & & & & \\
$\begin{array}{l}\text { Overall Model } \\
\text { Chaos }\end{array}$ & 2.32 & .021 & .20 & & & & \\
CBP & .84 & .405 & .07 & & & & \\
Stress & & & & & & & \\
Overall Model & & & & 11.33 & 154 & .000 & .12 \\
Chaos & 2.35 & .020 & .19 & & & & \\
CBP & 2.88 & .004 & .24 & & & & \\
\hline
\end{tabular}

CBP is Child Behavior Problems. Standardized B values are reported $N=156$

\section{Discussion}

We used a UK- based sample of families with young twins, to test household chaos and child behavior problems as predictors maternal well-being. There was an advantage of using a twin sample in that families with twins require more organization and effort in parenting, and previous studies have used twin samples to understand household chaos and child behavior problems [21-24]. Mothers perceiving more household chaos tended to report more depressive, stress and anxiety related symptoms. More child behavior problems also predicted more depressive and stress related symptoms, but it was not predictive of maternal anxiety. The results supported previous research indicating household chaos correlates with maternal well-being [2]. Notably, the results showed differentiation of maternal well-being in relation to child behavior problems. This highlights the importance of studying these aspects of maternal well-being separately.

We also demonstrated the independent prediction of chaos and child behavior problems with maternal well-being outcomes, in the context of existing literature that shows a link between child behavior problems and chaos [16-18]. The results indicate when chaos and child behavior problems put in the model together more chaos was a significant predictor of all well-being variables but for child behavior problems it was depression and stress. Results demonstrated that if mothers perceive more chaos and disorganization in the home, they may be at risk of having more depression, stress symptoms and anxiety. If they report more child behavior problems, they may also be at risk of having more depression and stress but not anxiety. These findings suggest that interventions focused on reducing the levels of chaos in the home, (e.g. implementing a regular bedtime routine, inducing calm and having an organized schedule) and/or reducing child behavior problems may also result in improved maternal well-being. The results can also imply that child behavior problems are risk factors for poor maternal well-being, highlighting the bi-directional influence mothers and children have on one another. 


\section{Limitations}

Despite the strengths of our novel study, we acknowledge some limitations. The current sample was mothers of twins and requires replication across different family types. Additionally, the sample was highly educated, $71.3 \%$ of the mothers reported having an undergraduate or higher degree, so the results cannot be generalized to all populations. Future studies should investigate whether the same pattern of results are apparent not only for parents of non-twin children, but also more representative samples in terms of education levels. Another point that worth mentioning is that the anxiety subscale showed poor internal reliability, which may have attenuated associations. Most important, a longitudinal design with all measures repeated over time would enable cross-lagged models to identify the temporal ordering of influence.

\section{Conclusion}

The current study showed that chaos predicted maternal depression, anxiety and stress, whereas child behavior problems were predictive of maternal depression and stress - but not anxiety. In order to have better outcomes for maternal well-being as well as for parenting, household chaos and child behavior problems should be targeted in interventions. The results suggest that child behavior problems and chaos are risk factors for impaired parental functioning.

Funding This study was funded by the Joseph Rowntree Foundation the Institute of Psychiatry at King's College London, and the University of Sussex.

\section{Declarations}

Ethical Approval All procedures performed in studies involving human participants were in accordance with the ethical standards of the institutional research committee and with the 1964 Helsinki declaration and its later amendments or comparable ethical standards.

Informed Consent Informed consent was obtained from all individual participants included in the study.

Open Access This article is distributed under the terms of the Creative Commons Attribution 4.0 International License (http://creativecommons.org/licenses/by/4.0/), which permits unrestricted use, distribution, and reproduction in any medium, provided you give appropriate credit to the original author(s) and the source, provide a link to the Creative Commons license, and indicate if changes were made.

Human and Animal Rights This article does not contain any studies with animals performed by any of the authors.

Conflict of Interest Sumeyra Yalcintas, Alison Pike, and Bonamy R. Oliver declares that she has no conflict of interest.

Open Access This article is licensed under a Creative Commons Attribution 4.0 International License, which permits use, sharing, adaptation, distribution and reproduction in any medium or format, as long as you give appropriate credit to the original author(s) and the source, provide a link to the Creative Commons licence, and indicate if changes were made. The images or other third party material in this article are included in the article's Creative Commons licence, unless indicated otherwise in a credit line to the material. If material is not included in the article's Creative Commons licence and your intended use is not permitted by statutory regulation or exceeds the permitted use, you will need to obtain permission directly from the copyright holder. To view a copy of this licence, visit http://creativecommons.org/licenses/by/4.0/. 


\section{References}

1. Belsky J. The determinants of parenting: A process model. Child Dev. 1984;55(1):83. https://doi. org/10.2307/1129836.

2. Pike A, Iervolino AC, Eley TC, Price TS, Plomin R. Environmental risk and young children's cognitive and behavioral development. Int J Beh Dev. 2006;30(1):55-66. https://doi.org/10.1177/0165025406062124.

3. Leerkes EM, Crockenberg SC. The development of maternal self-efficacy and its impact on maternal behavior. Infancy. 2002;3(2):227-47. https://doi.org/10.1207/S15327078IN0302_7.

4. Lovejoy MC, Graczyk PA, O’Hare E, Neuman G. Maternal depression and parenting behavior. Clin Psychol Rev. 2000;20(5):561-92. https://doi.org/10.1016/S0272-7358(98)00100-7.

5. Feldman R, Granat A, Pariente C, Kanety H, Kuint J, Gilboa-Schechtman E. Maternal depression and anxiety across the postpartum year and infant social engagement, fear regulation, and stress reactivity. J Am Acad Child Adolesct Psychiatry. 2009;48(9):919-27. https://doi.org/10.1097/CHI. 0b013e3181b21651.

6. Campbell SB, Pierce EW, March CL, Ewing LJ. Noncompliant behavior, overactivity, and family stress as predictors of negative maternal control with preschool children. Dev Psychopathol. 1991;3(2):175-90. https://doi.org/10.1017/S0954579400005228.

7. Clark LA, Watson D. Tripartite model of anxiety and depression: Psychometric evidence and taxonomic implications. J Abnorm Psychol. 1991;100(3):316-36. https://doi.org/10.1037/0021-843X. 100.3.316.

8. Wachs TD. Environmental chaos and children's development: Expanding the boundaries of chaos. 2005.

9. Nelson JA, O'Brien M, Blankson AN, Calkins SD, Keane SP. Family stress and parental responses to children's negative emotions: Tests of the spillover, crossover, and compensatory hypotheses. J Fam Psychol. 2009;23(5):671-9. https://doi.org/10.1037/a0015977.

10. Radke-Yarrow M, Nottelmann E, Martinez P, Fox MB, Belmont B. Young Children of Affectively Ill Parents: A Longitudinal Study of Psychosocial Development. J Am Acad Child Adolesc Psychiatry. 1992;31(1):68-77. https://doi.org/10.1097/00004583-199201000-00011.

11. Goodlin-Jones BL, Eiben LA, Anders TF. Maternal well-being and sleep-wake behaviors in infants: An intervention using maternal odor. 1998;18(4). https://doi.org/10.1002/(SICI)10970355(199724)18.4/378.AID-IMHJ5/3.0.CO.2-H.

12. Oddi KB, Murdock KW, Vadnais S, Bridgett DJ, Gartstein MA. Maternal and Infant Temperament Characteristics as Contributors to Parenting Stress in the First Year Postpartum: Temperament Characteristics and Parenting Stress. Infant Child Dev. 2013;22(6):553-79. https://doi.org/10.1002/ icd.1813.

13. Pike A, Atzaba-Poria N, Kretschmer T. Predictors of parenting: Family-wide and child-specific factors. Parenting. 2016;16(3):147-63. https://doi.org/10.1080/15295192.2016.1158599.

14. Evans GW, Lepore SJ, Shejwal BR, Palsane MN. Chronic Residential Crowding and Children's WellBeing: An Ecological Perspective. Child Dev. 1998;69(6):1514-23. https://doi.org/10.1111/j.14678624.1998.tb06174.x.

15. Smith EP, Prinz RJ, Dumas JE, Laughlin J. Latent models of family processes in African American families: Relationships to child competence, achievement, and problem behavior. J Marriage and Fam. 2001;63(4):967-80. https://doi.org/10.1111/j.1741-3737.2001.00967.x.

16. Dumas JE, Nissley J, Nordstrom A, Smith EP, Prinz RJ, Levine DW. Home Chaos: Sociodemographic, Parenting, Interactional, and Child Correlates. J Clin Child Adolesc Psychol. 2005;34(1):93-104. https://doi.org/10.1207/s15374424jccp3401_9.

17. Coldwell J, Pike A, Dunn J. Household chaos ? Links with parenting and child behavior. J Child Psychol Psychiatry. 2006;47(11):1116-22. https://doi.org/10.1111/j.1469-7610.2006.01655.x.

18. Dumas JE, Serketich WJ. Maternal depressive symptomatology and child maladjustment: A comparison of three process models. Behav Ther. 1994;25(2):161-81. https://doi.org/10.1016/S0005-7894(05) 80281-3.

19. Eyberg SM, Pincus DB. Eyberg child behavior inventory \& sutter-eyberg student behavior inventoryrevised: Professional manual. Odessa FL Psychol Assess Resour. 1999.

20. Crawford JR, Henry JD. The Depression Anxiety Stress Scales (DASS): Normative data and latent structure in a large non-clinical sample. Br J Clin Psychol. 2003;42(2):111-31. https://doi.org/10.1348/ 014466503321903544.

21. Deater-Deckard K, Mullineaux PY, Beekman C, Petrill SA, Schatschneider C, Thompson LA. Conduct problems, IQ, and household chaos: A longitudinal multi-informant study. J Child Psychol Psychiatry. 2009;50(10):1301-8. https://doi.org/10.1111/j.1469-7610.2009.02108.x. 
22. Hanscombe KB, Haworth CMA, Davis OSP, Jaffee SR, Plomin R. Chaotic homes and school achievement: A twin study: Chaotic homes and school achievement. J Child Psychol Psychiatry. 2011;52(11):1212-20. https://doi.org/10.1111/j.1469-7610.2011.02421.x.

23. Oliver BR, Pike A, Plomin R. Nonshared environmental influences on teacher-reported behavior problems: Monozygotic twin differences in perceptions of the classroom. J Child Psychol Psychiatry. 2008;49(6):646-53. https://doi.org/10.1111/j.1469-7610.2008.01891.x.

24. Wang Z, Deater-Deckard K, Petrill SA, Thompson LA. Externalizing problems, attention regulation, and household chaos: A longitudinal behavioral genetic study. Dev Psychopathol. 2012;24(3):755-69. https://doi.org/10.1017/S0954579412000351.

Publisher's Note Springer Nature remains neutral with regard to jurisdictional claims in published maps and institutional affiliations.

Sumeyra Yalcintas I started my Phd in 2017 with Prof. Alison Pike. I am interested in family dynamics, life span development, close relationships, and well-being.

In my masters I worked on maternal representations, more specifically how mothers' perceived partner responsiveness indirectly predict implicit infant attitude through implicit partner attitude. As well as, I worked as a graduate research assistant and coordinator in a project funded by The Scientific and Technological Research Council of Turkey.

Currently, I am working in a project that we run with Prof. Alison Pike, Making 3 to 4; Arrival of the Second-Child. In which we are investigating family dynamics in response and during the transition to having second child.

Alison Pike is a Professor of Child \& Family Psychology in the School of Psychology at the University of Sussex. Her research focuses on the antecedents and consequences of family relationships, with a particular focus on siblings, and differential experiences of children within the same family. This work has used crosscultural, family and twin designs to facilitate an understanding at multiple levels of analysis. Prof Pike has appeared as an expert on the BAFTA-nominated documentary series Secret Lives of 4-, 5-, \& 6-year-olds, and the Secret Lives of Brothers \& Sisters.

Bonamy Oliver I received my PhD from the Institute of Psychiatry, Psychology and Neuroscience (IoPPN), King's College London in 2006. Thereafter, I had various post-doctoral positions at IoPPN, as well as being Senior Research Lead for the National Academy for Parenting Research (2007-2009). I became Lecturer then Senior Lecturer at the University of Sussex (2012-2017) and was Senior Lecturer at Goldsmiths, University of London (2017-2020).

I joined UCL Institute of Education (IOE) as an Associate Professor in Developmental Psychology in July 2020, and am the Lead for the IOE Mental Health and Wellbeing in Education Network, as well as for the departmental Mental Health Research Group, Department of Psychology and Human Development. 